\title{
Tradición e innovación: un joven homérico en el inicio de la Eneida
}

\author{
Ana Clara Sisul \\ Depto. de Humanidades, Universidad Nacional del Sur / \\ CONICET, Argentina \\ anasisul@hotmail.com.ar
}

\section{Resumen:}

Entre los cuadros del templo de Juno en Cartago, Virgilio conduce la mirada de Eneas a uno particular: la muerte de Troilo tras su enfrentamiento con Aquiles. Esta escena anticipa los destinos de los jóvenes que se incorporan en la segunda mitad de la obra y, además, conlleva una contundente declaración poética (e ideológica) en torno a los temas que el autor considera necesario rescatar del silencio y el olvido, tanto en la literatura como en la historia, ya que Virgilio recupera y eterniza, en un soporte adecuado, un personaje del ciclo épico homérico significativamente ausente en la Iliada.

Palabras Clave: Eneida, Troilo, Tradición, Innovación.

\section{ABstract:}

Amidst the deeds depicted in Juno's Carthaginian temple, Virgil conducts Aeneas' eye to one small motif: Troilus' death after his encounter with Achilles. This emphasis anticipates the fate awaiting the youngsters who are to engage in the war, because it presents some contents reprised in the second half of the work. However, considering Troilus' absence in the Iliad (and his guaranteed survival in the Aeneid), the scene entails a strong poetic (and ideological) statement regarding what Virgil chooses to rescue from literature's silence and history's oblivion.

KeYwords: Aeneid, Troilus, Tradition, Innovation.

La extendida participación de personajes juveniles en la trama de la Eneida es una particularidad que no ha pasado desapercibida para la crítica. Entre la nómina de caracteres relevantes en el desarrollo del argumento, aquellos que no han alcanzado la madurez adulta representan una cifra considerable, especialmente al cotejarla con las obras homéricas, claro antecedente ${ }^{2}$. La distinción es notoria: los héroes de la guerra de Troya eran hombres maduros, padres de familia en la mayoría de los casos, que al iniciar la acción de la Ilíada habían transcurrido casi una década en situación de asedio y, por ende, contaban con una vasta experiencia bélica. En cambio, en la Eneida, Virgilio destaca las historias de algunos personajes juveniles, insertos precipitadamente en una guerra que supera sus posibilidades reales de acción.

La filiación entre la epopeya romana y sus predecesoras griegas es un hecho fuera de discusión ${ }^{3}$. Virgilio alude a ellas reiteradamente, sobre la base de un movimiento dual: señalar su pertenencia a la tradición y, a la vez, defender su independencia, es decir, la adecuación de sus licencias artísticas, actualizando el sentido de la señera frase de la Bucólica quinta: ... alter ab illo (Verg., Ecl. V.49) ${ }^{4}$. La presentación de los episodios de la guerra de Troya en el templo de Juno en Cartago ejemplifica la capacidad virgiliana de armonizar tradición e innovación, porque allí, con admirable calidad artística, el poeta logra resumir todo el sufrimiento de una guerra en menos de diez cuadros ${ }^{5}$ : los primeros choques armados, el ominoso robo de los caballos de Reso, la muerte de Troilo, los ruegos vanos de las troyanas, la muerte de Héctor, la entrega del cuerpo a su padre y los últimos días de lucha, representados en la tardía aparición de Pentesilea ${ }^{6}$. Entre esta serie de intensas imágenes, que llegan al lector a través de los ojos de Eneas, nos interesa la tercera -Troilo-, pues resulta cuanto menos curioso que, en medio de los horrores de una guerra extendida durante una década, donde abundan 
tragedias, pero también demostraciones del más elevado heroísmo por parte de guerreros consagrados, el autor se detenga en la muerte de un joven inexperto:

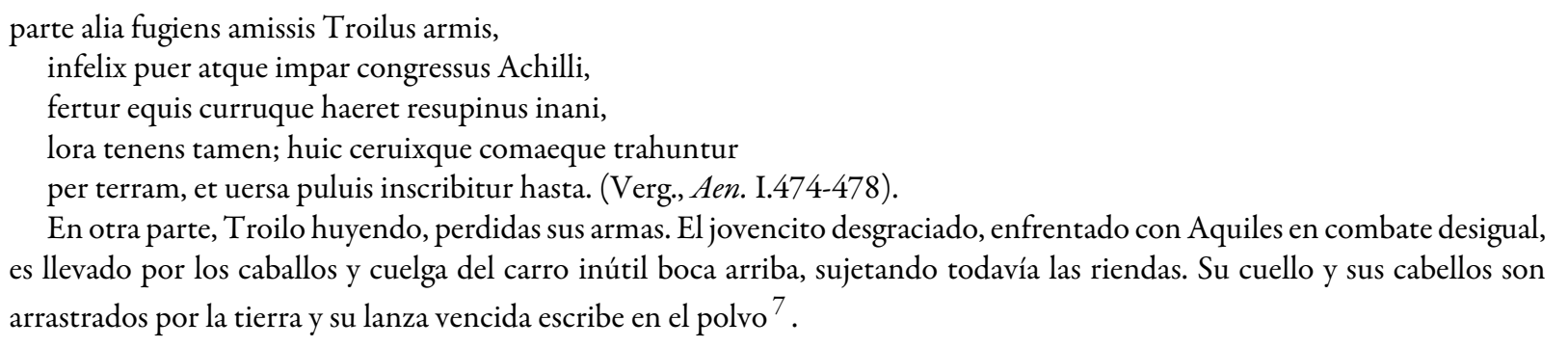

En este trabajo sostenemos que la presencia de Troilo en los albores de la Eneida constituye una declaración metaliteraria de Virgilio, quien recupera la marginalidad del personaje en la tradición homérica (representada en una escritura efímera sobre un soporte precario: ... puluis inscribitur hasta) y se posiciona como una alternativa, destacándolo. Adicionalmente, consideramos que esta estrategia tiene ramificaciones trascendentes, pues Troilo, en su carácter de joven víctima de una mors immatura, garantiza la misma visibilidad y pervivencia a todos sus coetáneos virgilianos, instaurando una visión capaz de superar los términos de una tradición (literaria, pero también histórica) que ignora sistemáticamente las pérdidas menores que cimientan el avance de los grandes imperios.

Con este objetivo, en primera instancia desglosaremos la repetición de algunos rasgos de Troilo en las figuras juveniles de los cantos finales de la Eneida ${ }^{8}$, para demostrar que el hijo menor de Príamo funciona como anticipatio de aquellas. A continuación, desarrollaremos cómo la pervivencia (y supervivencia) de un joven del ciclo homérico en la obra virgiliana constituye una reflexión metaliteraria que se supera a sí misma y deviene un posicionamiento ideológico.

\section{Troilo como ANTICIPATIO}

La caracterización de Troilo como infelix puer resuena parcialmente en otros personajes virgilianos (Euríalo, Niso, Palante, Lauso y Camila) golpeados por la tragedia de la muerte prematura, conformando una trama subtextual apuntalada en la confluencia de juventud e infelicitas ${ }^{9}$. La decisión de dejar este término en latín no es arbitraria: el adjetivo infelix posee una particular ambigüedad semántica que dificulta su traducción al español, al estar liado tanto a la adversidad como a la inmadurez sexual de sus receptores, incapaces de procrear ${ }^{10}$. En consecuencia, infelix no solo refiere el aciago destino de Troilo, sino también su falta de descendencia, que refuerza la imprudencia de su participación en la guerra, pues su deceso vulnera la continuidad de su núcleo familiar ${ }^{11}$. En el transcurso de la Eneida, otras muertes juveniles conllevan un trágico sentido final, en tanto truncan la descendencia de antiguas líneas genealógicas, carentes de herederos ${ }^{12}$. La atribución del adjetivo infelix a la madre de Euríalo (Verg., Aen. IX.477), aMecencio (Verg., Aen. X.850) y a Evandro (Verg., Aen. XI.53 y 175) funciona en este sentido, porque sus años les impedirían volver a tener descendencia ${ }^{13}$. La mors immatura posee repercusiones sociopolíticas que exceden el luto privado de los parientes más cercanos al difunto: cada una de estas pequeñas tragedias trasciende su singularidad, para mostrar las invaluables pérdidas que toda guerra supone ${ }^{14}$.

Esta situación se aprecia con claridad en el caso de Marcelo, joven histórico víctima de una muerte prematura, que, en la representación virgiliana -y debido a la insistente yuxtaposición de casos similaresparece señalar una incertidumbre en relación con la proyección futura de la obra de Augusto ${ }^{15}$. En reiteradas ocasiones en el transcurso de la Eneida, Virgilio disemina elementos que conducen a cuestionar la firmeza de las bases del imperio. Los decesos anticipados de personajes juveniles son uno de los principales motivos y, si bien Ascanio sobrevive, abriendo el camino a la posteridad ${ }^{16}$, Marcelo vuelve a instaurar el patrón cíclico de 
muertes prematuras sacrificiales. Evidentemente, la vulnerabilidad de las generaciones más jóvenes desvelaba a Virgilio.

El siguiente punto anticipatorio en la descripción ekphrástica del deceso de Troilo recae en su encuadramiento en el marco de una batalla desigual con Aquiles: impar congressus. En la Eneida, este patrón se reitera en los trágicos choques entre guerreros experimentados y jóvenes inmaduros, que otorgan al canto décimo su característica simetría argumental. Las batallas entre Palante y Turno, por un lado, y Lauso y Eneas, por el otro, establecen un diálogo basado en sus incontestables similitudes y sus meticulosamente diagramadas divergencias ${ }^{17}$ :

...hinc Pallas instat et urget,

hinc contra Lausus, nec multum discrepat aetas,

egregii forma, sed quis Fortuna negarat

in patriam reditus. ipsos concurrere passus

haud tamen inter se magni regnator Olympi;

mox illos sua fata manent maiore sub hoste. (Verg., Aen. X.433-438).

De este lado, Palante asalta y presiona; de este otro, en contra, Lauso. Sus edades no distan mucho y sobresalen por su

belleza, pero la Fortuna les había negado el retorno a la patria. El rey del gran Olimpo no permitió que peleen entre sí; sus destinos los esperan pronto en un enemigo mayor.

Recurriendo al cambio de fortuna trágico, Virgilio aproxima a dos jóvenes que podrían haber sido antagonistas semejantes, destinados a encontrarse y luchar justamente, y, en cambio, son arrastrados por sus propias decisiones al postrer encuentro con enemigos mayores. Este asimétrico diseño marcial es una marca distintiva del décimo canto y, a su vez, constituye la causa inmediata de las muertes de los dos personajes menores, pues el resultado de los combates no depende de una mayor destreza o pericia en el manejo de las armas, punto que determinaría una batalla justa, de la que el vencedor podría sentirse orgulloso. Al contrario, el desenlace se vincula con el predominio de un factor claramente arbitrario: la edad ${ }^{18}$.

En definitiva, la juventud, la muerte prematura -con la consecuente extinción de grupos familiares-, así como el enfrentamiento con oponentes superiores en fuerzas y experiencia constituyen los contundentes aspectos que vinculan a Troilo con los jóvenes virgilianos posteriores, y justifican, en gran medida, el interés del autor por recuperarlo en el primer canto de su obra. Un muchacho inexperto e invisible en el argumento de la Ilíada ${ }^{19}$ reaparece en otros, virgilianos, que comparten la primera de sus dos señas (la inexperiencia), pero se distinguen en el segundo punto (la invisibilidad), ya que Virgilio, como veremos a continuación, los coloca en el foco de atención del lector a lo largo de la trama de su epopeya.

\section{Troilo COMO DECLARACIÓN METALITERARIA E IDEOLÓGICA}

La incorporación de Troilo en la Eneida trasciende una estrategia meramente anticipativa y se transforma en una declaración poética: al destacar su figura, Virgilio sugiere que la Eneida recorrerá caminos que Homero no transitó. La centralidad de la muerte de Troilo en la composición del panel cartaginés constituye un recorte particular, que acentúa un motivo ausente en la Ilíada (cuyo aliento argumental no incluye la narración de la Ilioupersis, de la que el joven es involuntariamente, pero, en gran medida, responsable) y se justifica en el especial trasfondo del texto virgiliano, involucrado con la tragedia de las muertes precoces.

El compromiso de Virgilio con la exposición de un tema tan delicado como la mors immatura se relaciona con su voluntad por incorporar en la obra las voces que la guerra acalla ${ }^{20}$. En la Eneida, la tragedia de la muerte juvenil repercute en una sucesión de significativos silencios, que el autor yuxtapone en un crescendo abrumador. En primer lugar, se destaca el mutismo artístico de Dédalo ${ }^{21}$, incapaz de esculpir en el mármol el aciago destino de su hijo: 
partem opere in tanto, sineret dolor, Icare, haberes.

bis conatus erat casus effingere in auro,

bis patriae cecidere manus... (Verg., Aen. VI.30-33).

Tú también hubieses tenido una gran parte en semejante obra, Ícaro, si el dolor lo hubiese permitido. Dos veces intentó tallar lo ocurrido en el oro; dos veces cayeron sus manos paternas.

Esta esterilidad creativa (pero asimismo comunicativa) es luego aludida por Evandro, al anticipar que la pérdida de Palante supondría para él un dolor inefable ${ }^{22}$ :

sin aliquem infandum casum, Fortuna, minaris,

nunc, nunc o liceat crudelem abrumpere uitam (Verg., Aen. VIII.578-579).

Sin embargo, Fortuna, si me amenazas con algún hecho inefable, mejor que ahora ioh, que ahora! se me permita interrumpir esta cruel vida.

Su predicción se ve posteriormente confirmada en el eximio hilo de voz con que pronuncia su lamento funerario: et uia uix tandem uoci laxata dolore est ("y con dificultad por el dolor se desató el camino de su voz") (Verg., Aen. XI.151).

Adicionalmente, esta inefabilidad se aplica, transformada, al tercer progenitor que ve la muerte de su descendencia en la Eneida: la madre de Euríalo:

...at subitus miserae calor ossa reliquit,

excussi manibus radii reuolutaque pensa.

euolat infelix et femineo ululatu

scissa comam muros amens atque agmina cursu

prima petit, non illa uirum, non illa pericli

telorumque memor, caelum dehinc questibus implet (Verg., Aen. IX.475-480).

Pero súbitamente el calor abandonó los huesos de la mísera, las agujas cayeron de sus manos y los ovillos se enredaron. Se precipita la desgraciada, mesándose los cabellos con un aullido femenino, y, enloquecida, busca en su carrera los muros y las primeras filas. No recuerda los soldados, los peligros, ni las flechas y, a continuación, colma el cielo con sus lamentos.

Ante la luctuosa novedad que llega a sus oídos, la madre de Euríalo grita, arranca sus cabellos y experimenta pérdida del calor corporal y frenetismo ${ }^{23}$. Estas manifestaciones de dolor, típicamente femeninas, se ven precedidas por otro síntoma: al oír la noticia, la anciana abandona el tejido, las agujas caen de sus manos y las madejas de lana se enredan. Considerando la afinidad semántico-etimológica entre tejido y texto ${ }^{24}$, la imagen supone un mutismo simbólico. Las palabras enmudecen en las gargantas, como las madejas se enredan en sus cestos, impidiendo el habla, la escritura, el tejido ${ }^{25}$.

No de otro modo, volviendo al cuadro con el que comenzamos este trabajo, en la tradición previa a la Eneida la historia de Troilo se escribe sobre el polvo, con el trazo tembloroso de la lanza arrastrada por el carro (...et uersa puluis inscribitur hasta enVerg., Aen. I.478). Esta escritura es efímera y recuerda las palabras de Catulo $^{26}$ :

sed mulier cupido quod dicit amanti

in uento et rapida scribere oportet aqua. (Catul. LXX.3-4).

Pero lo que una mujer dice a su apasionado amante conviene escribirlo en el viento y en el agua que corre rápida.

Sin embargo, el sentido de los versos es irreductible, como también la carga emotiva de uno y otro contexto: a la caducidad de las amorosas palabras femeninas se contrapone la caducidad de un destino humano y, aun peor, el de un joven con toda la vida por delante.

Virgilio presenta la inestabilidad de la historia de Troilo, escrita en el polvo ${ }^{27}$, para contraponerla con la materialidad de las imágenes del templo de Juno, donde el relato de la gesta del joven se preserva en un soporte apropiado, sobreviviendo en el tiempo ${ }^{28}$. La Eneida es también un templo de mármol (cf. Verg., G. III.10-14), que protege la memoria de todos los hombres caídos en la guerra. El desarrollo del argumento confirma este 
patrón aquí consignado, pues Virgilio se preocupa por rescatar las historias menores de los jóvenes inexpertos muertos precozmente ${ }^{29}$, que, a pesar de no ser héroes ${ }^{30}$, quedan así incorporados al templo, que es la obra.

De esta manera, el autor se posiciona frente a la tradición literaria homérica, sumando voces menores al paradigma épico. Asimismo, estas historias dialogan conflictivamente con el relato oficial, imperial y dinástico, estableciendo un texto polifónico ${ }^{31}$, donde ninguna verdad está dada por naturaleza y el sentido global se construye en la tensa armonía de la sumatoria de cada una de sus partes.

\section{Notas}

1 Este trabajo ha sido posible gracias a un subsidio para investigación otorgado por la ANPCyT, PICT-2016-1012, a otro de la SGCyT de la Universidad Nacional del Sur, PGI 24/I227 y a un tercero del CONICET, PIP 2014-2016 n 0089.

2 La preeminencia de los jóvenes en la Eneida, en comparación con las epopeyas homéricas, es mencionada, entre otros, por Gransden, K. W., Virgil. The Aeneid, Cambridge, 1990, 33: "Youth was not a notable feature of Homer's warriors who had all been fighting for ten years when the poem opens, whereas many of the young men who fought in Latium were untried warriors, in action for the first time".

3 En este sentido, recuperamos los postulados de Hardie, P., Virgil, Oxford, 1998, 54: "The Aeneid is alive to the whole of the epic tradition, but it looks back continuously to the origins of that tradition in the poems of Homer", que se basa en Clausen, W., "An interpretation of the Aeneid", HSPh 68, 1964, 139-147, 139: "Virgil uses Homer as he uses Apollonius of Rhodes, or Ennius, or Lucretius; but with this difference: Homer was for Virgil the archetypal poet, the grand original".

4 Las citas de las obras virgilianas proceden de la edición crítica de Mynors, R. A. B., (ed.) Vergilii Maronis Opera, Oxford, 1969.

5 Seguimos a Weiden Boyd, B., "Non enarrabile textum: ecphrastic trespass and narrative ambiguity in the Aeneid", Vergilius 41, 1995, 71-90,76: “...lines 456-65, taken together, serve as an introduction to the ecphrasis, rather than being a part of the ecphrasis itself".

6 Ver Horsfall, N., "Dido in the light of History", en: Harrison, S. J. (ed.), Oxford readings in Vergil's Aeneid, Oxford, 1990, 127-140, 138, para una interesante interpretación de estos cuadros: "Just as one would expect in a temple of Juno, the choice of pictures illustrates the success of her favourites: while Aeneas is delighted to see that Troy is not forgotten, he quite fails to observe, as we must do, that the attitude to Troy shown in these pictures is neither friendly nor sympathetic". Sobre el potencial de interpretación errónea de un objeto ekphrástico, ver Weiden Boyd, "Non enarrabile textum", 73-74.

7 Todas las traducciones presentadas son de nuestra autoría.

8 Este punto ya fue notado por Putnam, M. J. C., Virgil's epic designs. Ekphrasis in the Aeneid, New Haven - Londres, 1998, 31: "One infelix puer and his tragedy, depicted in the presentness of art, anticipate, as paradigm, the several ill-fated youths, from Marcellus to Turnus, whose misfortunes mark the epic's course”. En las páginas subsiguientes, desarrollaremos las convergencias.

9 Euríalo recibe el calificativo puer en Verg., Aen. V.296, IX.182, 217, 276 y, por otra parte, es denominado infelix en Verg., Aen. IX.390. Niso, un poco mayor que su compañero, no es objeto del término puer, aunque se lo denomina infelix en dos oportunidades: Verg., Aen. V.329 y IX.430. Lauso es llamado puer en Verg., Aen. X.825 e infelix en Verg., Aen. X.829. Palante es puer en Verg., Aen. VIII.581, XI.42, XII.943. Camila es un caso particular, pues, por tratarse de una mujer, nunca es llamada puer (ni su variante femenina, puella) aunque se refiere su infelicidad en Verg., Aen. XI.563. Por otra parte, Marcelo, Lauso y Palante son receptores del sintagma miserande puer (Verg., Aen. VI.882, X.825 y XI.42), que funciona en el mismo sentido.

10 En la definición de felix provista por el Oxford Latin Dictionary se distinguen las ocasiones en que el adjetivo se atribuye a vegetales, árboles, terrenos o estaciones: "Fruitful, productive (...) rich, fertile", de aquellas en que se adjunta a personas: "Enjoying good fortune, blessed, fortunate" (OLD, 684). La ambivalencia también figura en Ernout, A. \& Meillet, A., Dictionnaire étimologique de la Langue Latine, París, 2001 [1959], 224: "qui produit des fruits, fécond (= ferax), fertile ... favorisé des dieux, heureux..." En cambio, Bellincioni, M., s.v. "Felix", en: EV II (1988), 486 articula ambas acepciones: "L'uso virgiliano di felix ricopre più o meno tutta la gamma semantica del termine, al cui senso originario di 'fecondo', 'fertile' risalgono in modo più o meno diretto le altre accezioni”. Confluyen en esta interpretación Weiden Boyd, B., "Cydonea mala: Virgilian word-play and allusion”, HSCP 87, 1983, 169-174, especialmente p. 171 y Gagliardi, P., "Fortunatus in Virgilio", REL 87, 2009, 92-113, especialmente p. 95. El empleo de infelix con un sentido ligado a la esfera de la botánica, extensiva a la infertilidad de los hombres, se condice con los desarrollos de Fernández Martínez, donde la autora hace un extenso recorrido por los sentidos de acerbus en la literatura latina de tiempos de Virgilio, 
para concluir en la presencia de una conjunción semántica entre agrio (por el fruto no maduro) y prematuro: "En tres ocasiones, sin embargo, ha prevalecido, dentro del mismo campo semántico, la metáfora 'la vida del hombre es como la de los frutos', de forma que si un fruto recogido o caído antes de tiempo resulta acerbus, también la muerte prematura (así como el dolor o las heridas causadas por ésta) resultará acerba" (Fernández Martínez, C., "Acerbus: la amargura de morir antes de tiempo", Emerita 71/2, 2003, 313-337, 322).

11 En relación con este punto, corresponde mencionar la existencia de un mito, según el cual Troya jamás caería si Troilo alcanzaba los veinte años. Esta teoría se sostiene en el cuadro del templo de Juno inmediatamente anterior al del desafortunado joven: los caballos de Reso, portadores de un sentido equiparable en relación con la pervivencia de la urbe oriental. Sobre este último punto, ver Serv., A. I.469: abductique sunt equi, quibus pendebant fata Troiana, ut, si pabulo Troiano usi essent vel de Xantho Troiae fuvio bibissent, Troia perire non posset ("Son robados los caballos, de los cuales dependían los destinos troyanos, de manera que, si hubiesen consumido las pasturas troyanas o hubiesen bebido del río Janto, Troya no hubiese podido perecer"). La cita al comentario de Servio procede de Thilo, G. \& Hagen, H. (eds.), Commentary on the Aeneid of Virgil, Cambridge, 2011 [1878-1902]. Al presentar el destino de la ciudad en estrecha dependencia con la supervivencia de Troilo, Virgilio alude a la necesidad de salvaguardar las nuevas generaciones, pues en sus hombros descansa el futuro de los pueblos. Cf. Putnam, Virgil's epic designs, 39-40.

12 Block, E., "Failure to thrive: the theme of parents and children in the Aeneid, and its Iliadic models", Ramus 9, 1980, 128-149, 145: "The reader of the Aeneid is confronted with a tension in the poem which cannot be dispelled: himself living in the future from the poem's perspective, he sees repeatedly the defeat of this future in the poem".

13 Ratti, S., "Le sens du sacrifice de Camille dans l'Énéide (11, 539-566)”, Hermes 134/4, 2006, 407-418, 415: “...l'adjectif infelix peut aussi s'appliquer à un père qui connaît l'horreur de perdre ses fils”. En relación con la vejez de la madre de Euríalo, ver Verg., Aen. IX.284-285, 481-482 y 489. La avanzada edad de Evandro se menciona en reiteradas ocasiones, pero el fragmento más representativo se encuentra en Verg., Aen. VIII.560-563, donde el rey relata las proezas de su lejana juventud. Para Mecencio, nos remitimos al significativo momento (posterior a la muerte de Lauso), en el que se refieren sus canas por primera vez (Verg., Aen. X.844) y que ha sido correctamente interpretado por Glenn, J., "The fall of Mezentius", Vergilius 18, 1972, 10-15 y Elftmann, G., "Aeneas in his prime: distinctions in age and the loneliness of adulthood in Vergil's Aeneid”, Arethusa 12/2, 1979, 175-202, (particularmente, p.189).

14 Sobre la contaminación del ambiente privado en la esfera pública, nos remitimos al libro de Ford Wiltshire, S., Public and private in Vergil's Aeneid, Amherst, 1989, particularmente 54-55: "None of these deaths, however, does Virgil leave unattended. Into each of them he introduces the 'lesser' world of affiliative bonds and sacrificial affection..." Es ineludible también la referencia a los estudios de Petrini, M., The child and the hero. Coming of age in Catullus and Vergil, Ann Arbor, 1997, 9-10: "The deaths of children in the Aeneid are not mere pathos, nor are they only individual losses and particular tragedies. They represent the loss of renewal ... Without renewal there can be no hope, no change, no escape from the patterns of history".

15 Johnson, W. R., Darkness visible. A study of Vergil's Aeneid, Berkeley - Los Angeles, 1976, 107 define la muerte de Marcelo como: "...a tragedy, indeed a bitterness, that threatens to overwhelm the magnificence of Roman achievement", pero analiza su sentido profundo en términos emotivos y no politicos. Quint, D., "Repetition and ideology in the Aeneid", MD 23, 1989, 9-54, 25, en cambio, considera las importantes repercusiones sociopolíticas implicadas en su deceso: "The question of Rome's own futurity is addressed by the death of one more son, Marcellus, at the middle of the poem (6.860-886), a death that raises questions about the imperial succession and the stability of Augustus's political achievement". Hardie, P., "Virgil and tragedy", en: Martindale, C. (ed.), The Cambridge companion to Virgil, Cambridge, 1997, 312-326, 318 trabaja en este mismo sentido: “...the continuity not so much of the 'Roman race', but of the Julian gens (789-90 omnis Iuli | progenies) was threatened by his death, starkly revealing the fragility of a system in which the security of the state depends on the physical survival of one man and his heir". Martínez Astorino, P., "Representaciones de la historia republicana y reciente: Marcelo en Virgilio y Propercio”, Maia 66/2, 2014, 333-351, 347 dialoga con este autor, al expresar que el sentido de la muerte de Marcelo trasciende el plano político y se relaciona directamente con un motivo trágico predilecto de Virgilio: el de los costos del avance imperial: "En el plano sociopolítico, Virgilio parece sostener algo más medular y a la vez general: que la eminencia futura romana estará ligada a la experiencia del dolor y de la muerte (...) El futuro poder de la res Romana entrañará muchas veces la muerte de los propios (representados en la obra por Marcelo, Niso, Euríalo, Palante) y asimismo las dolorosas muertes de los vencidos (Dido, Lauso, Camila, Turno y tantos otros personajes menores), de las que el poeta conmovedoramente se lamenta. La grandeza romana está construida sobre un inmenso, inefable dolor..." Otros autores ven el fragmento de manera (según nuestro criterio, excesivamente) optimista: "Ainsi conçue comme le sacrifice préparatoire à un rénouveau, la mort de Marcellus, quelque cruelle qu'elle soit, est l'annonce, pour Rome, d'une proche renaissance” (Dupont, F. \& Neraudau, J. P., "Marcellus dans le chant VI de l'Énéide", REL 48, 1970, 259-276).

16 Ascanio es el receptor privilegiado del término puer en la Eneida: Verg., Aen. I.267, 678, 684, 714; II.598; III.339, 341, 487; IV.156, 354; V.74, 569, 599; IX.656; X.70, 236, 605; XII.435. Su particularidad consiste en su supervivencia sin ser objeto de una caracterización que involucre el adjetivo infelix, como manda el sentido dinástico (al menos en una 
primera lectura) de la obra. Sobre este tema, ver el reciente libro de Rogerson, A., Virgil's Ascanius: imagining the future in the Aeneid, Cambridge, 2017.

17 En relación con las batallas desiguales ver McDermott, E. A., "The 'unfair fight': a significant motif in the Aeneid", CJ 75/2, 1979, 153-155 y Horsfall, N., "Non uiribus aequis: some problems in Virgil's battle-scenes”, G\&R 34/1, 1987, 48-55. Putnam, Virgil's epic designs, 45 sostiene la prioridad del cuadro de Troilo como instancia anticipatoria: "The graphic death of Troilus anticipates the several occasions in the final battles where a less experienced and usually younger warrior contends with one more powerful". Sin embargo, considera que las referencias intratextuales se extienden más allá del décimo canto, hacia el duodécimo, en el asimismo desigual combate entre Eneas y Turno. Anteriormente, Lowenstam, S., “The pictures of Juno's temple in the Aeneid", CW 87/2, 1993, 37-49, especialmente 39-40, analizaba las repercusiones del cuadro de Troilo en los duelos asimétricos del canto décimo. Sobre estos, ver también Conte, G. B., Virgilio. Il genere e i suoi confini, Milán, 1984, 89-90 y La Fico Guzzo, M. L., Espacios simbólicos en la Eneida de Virgilio, Bahía Blanca, 2005, 299. La voz autoral acentúa el desequilibrio en el choque entre Palante y Turno: uiribus imparibus (Verg., Aen. X.459) y Eneas también menciona la audacia de Lauso, al atreverse a luchar contra él: ...maioraque uiribus audes? (Verg., Aen. X.811).

18 Como consta en las palabras de Evandro ante el cuerpo de su hijo: tu quoque nunc stares immanis truncus in aruis, / esset par aetas et idem si robur ab annis, / Turne... (Tú también, Turno, estarías ahora, un tronco enorme en el campo, si hubiese sido la edad similar e igual la fuerza de los años) (Verg., Aen. XI.173-175).

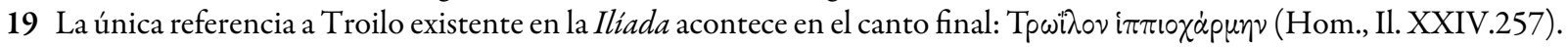
Cita extraída de la edición crítica de Monro, D. B. \& Allen, T. W. (eds.), Homeri Opera, Oxford, 1954.

20 En este punto, nos guía el concepto de polifonía, aplicado a la obra virgiliana por Conte, Virgilio. Il genere, especialmente 67-70, y certeramente reelaborado por Lyne, R. O. A. M., Further voices in Vergil's Aeneid, Oxford, 1987, 2, al plantear la teoría de las further voices: "Devices are exploited to insinuate ramifying meanings and messages for those prepared to listen. Further voices intrude other material and opinions, and these may be disturbing, even shocking. Further voices add to, comment upon, question, and occasionally subvert the implications of the epic voice". Actualmente, la mayoría de los críticos reconoce la vigencia de una línea narrativa oficial, acorde con los postulados del poder de Augusto, bajo cuya égida se sitúa el autor, la cual, no obstante, se ve constantemente subvertida por el trabajo erosivo de las voces alternativas. Así, por ejemplo, sostiene Quint, D., Epic and empire. Politics and generic form from Virgil to Milton, Princeton, 1993, 23: "The imperial ideology that is articulated in these verses is not identical to the 'meaning' of the Aeneid, which devotes a considerable part of its energy to criticizing and complicating what it holds up as the official party line". En este sentido se expresa también Galinsky, K., "Intención autoral y libertad de recepción en el arte y poesía augustea", Auster 1, 1996, 15-31, 24, quien, a pesar de tu postura crítica de los postulados de la escuela de Harvard, define el arte augustal como uno donde predomina una "multiplicidad intencional de significados", los cuales, de todas formas, “...opera[n] dentro del marco de un significado global claramente establecido".

21 Putnam, Virgil's epic designs, 82: "Death renders this artist artless".

22 Por tratarse de un derivado de fare, el matiz semántico de nefandus se extiende hacia el terreno de la (in)comunicabilidad, como constata la entrada de fandus en el Oxford Latin Dictionary: "That may be spoken of or said; esp. w. neg. or w. nefandus, proper lawful” $(O L D, 676)$. Esta acepción es constatada por Maltby, R., A lexicon of ancient latin etymologies, Wiltshire, 1991, 407, al referir al sentido comunicativo del término. A su vez, Ernout \& Meillet, Dictionnaire étimologique, 217 confirman la etimología: "Les anciens rapprochent fās et fästus du verbe färi ... Virgile donne pour génitif à fäs le gérondif fändi..." El aspecto comunicativo de fando y sus derivados es trabajado por Bettini, M., "Weighty words, suspect speech: fari in Roman culture", Arethusa 41/2, 2008, 313-375, 350, quien establece una conexión con la esfera social de la comunicación al sostener que "Fando, a unique impersonal form of the verb fari, defines a kind of scattered discourse referring to stories that circulate..."

23 Nugent, G. “The women of the Aeneid: vanishing bodies, lingering voices”, en: Perkell, C. (ed.), Reading Vergil's Aeneid: an interpretive guide, Norman, 1999, 251-270, especialmente 253-255, incluye la centralidad del sufrimiento como una de las tres características principales de las figuras femeninas virgilianas. Zarker, J. W., "Vergil's trojan and italian matres", Vergilius 24, 1978, 15-24, 22 analiza los diferentes papeles de las mujeres en la obra y concluye: "The matres whether Iliades or Latinae, are the real victims of epic heroism. They are the persons without a voice in the epic decisions; yet they pay the terrible costs of war". Ford Wiltshire, Public and private, 52 concuerda con esta interpretación: "For this mother the official themes of the epic -arma uirumque cano- cease to exist. She experiences only the costs".

24 Ernout \& Meillet, Dictionnaire étimologique, 690 definen texo como: “...tramer, entrelacer. Se dit non seulement de la toile, mais de tout ouvrage dont les matériaux s'entre-croisent ou s'enchevètrent”. A continuación, se listan tanto tela como texto entre sus acepciones.

25 También podría interpretarse en este sentido la demora en la mención al nombre de Marcelo en el discurso de Anquises en los Campos Elíseos, trabajada por Goold, G. P., "The voice of Virgil: The pageant of Rome in Aeneid 6", en: Woodman, T. y Powell, J. (eds.), Author and audience in Latin literature, Cambridge, 1992, 110-123, particularmente 120 ss.. 
26 Sobre intertextualidad entre Virgilio y Catulo, ver Armstrong, R., "The Aeneid: inheritance and empire", en: Clarke, M. J., Currie, B. G. F. y Lyne, R. O. A. M. (eds.), Epic interactions. Perspectives on Homer, Virgil, and the epic tradition presented to Jasper Griffin, Oxford, 2006, 131-157, particularmente, p.154, donde la autora sostiene: "The most obvious allusions to Catullus ... come at points of high emotion”. La cita catuliana procede de la edición canónica de Mynors, R. A. B., (ed.), Carmina, Oxford, 1958.

27 Las relaciones entre el polvo y la mortalidad se constatan en las palabras del Génesis III 19: Memento homo, quia pulvis es et in pulverem reverteris ("Recuerda, hombre, que polvo eres y al polvo retornarás"). Ver Cirlot, J., Diccionario de simbolos, Barcelona, 1981, 375: “...estado de máxima destrucción, aún perceptible, de la forma más baja de la realidad a la metrología humana. Por tanto, el polvo, como la ceniza (aunque ésta concierne al fuego y el polvo a la tierra), tiene un sentido negativo relacionado con la muerte".

28 Putnam, Virgil's epic designs, 31: "Ekphrasis here fosters such a collusion, of writing in war and writing of war, of dust and permanence, of the 'turns' on which linear writing depends that also both mimic the reversals, and therefore portend the ultimate moment of mortality, which fate brings even to the young". Seider, A., Memory in Vergil's Aeneid: creating the past, Cambridge, 2013, 83 sostiene que el descubrimiento de las imágenes de la guerra de Troya en el templo de Juno llena a Eneas y a sus hombres de esperanza, en tanto estos valoran la preservación de la memoria: "Consignment to oblivion ... has been averted. Although the visual reminders of these destructive events certainly bring Aeneas pain, the mere fact that the Trojans are remembered offers a measure of hope as well". Berlin, N., "War and remembrance: Aeneid 12.554-60 and Aeneas' memory of Troy", AJPh 119, 1998, 11-41, 12: "Within and without, this epic is motivated by and motivates memory...”

29 Ver Verg., Aen. IX.446-449 y X.791-793. Block, "Failure to thrive", 135: “Admittedly, great achievements require sacrifice, and all wars consume young men”. Basson, W. P., "Vergil's Camilla: A paradoxical character", AClass 29, 1986, 57-68, 57: "And among the sacrifices that such a war exacts, not the least are those demanded of talented young people in their prime”. Lyne, Further voices, 200: "All sort of prices had to be paid for 'imperium sine fine'”. Perutelli, A., La poesia epica latina, Roma, 2000, 110 habla de "poetica del dolore e dei vinti".

30 En ningún punto de la obra recibe un muchacho virgiliano el adjetivo heros. El guerrero más joven en ser calificado de esta manera es Turno (Verg., Aen. XII.723 y 902), quien posee algunas características etarias que lo apartan de los personajes netamente juveniles.

31 Ver Conte, G. B., The rhetoric of imitation. Genre and poetic memory in Virgil and other latin poets, Nueva York, 1986, 157: "With the multiplicity of points of view introduced by Virgil to complicate the norm, the text, as noted above, becomes polycentric. Each point of view, as it becomes poetically active, not only tends to take on the autonomous meaning of one who understands only himself but also tends to assert its own predominance within the text. Each point of view lays claim to the truth about the world that it represents and, by ignoring every other point of view, seeks to arrange all real or possible events within its own horizon". 